\title{
In vitro investigation of antioxidant and antihemolytic activities of three Lamiaceae species from Morocco
}

\author{
Abdelbassat Hmidani ${ }^{1,2^{*}}$, Eimad dine Tariq Bouhlali ${ }^{3}$, Mohammed Ajebli ${ }^{4}$, Tarik Khouya ${ }^{2}$, Mohamed Benlyas ${ }^{1}$ and \\ Chakib Alem²
}

\begin{abstract}
Background: Lkhzama (Lavandula officinalis), Mard-doch (Origanum majorana), and Lahbak (Ocimum basilicum) are aromatic and medicinal plants widely used in Moroccan folk medicine as a treatment for numerous diseases including liver diseases, rheumatism, and diabetes. This study was undertaken to examine the antioxidant and antihemolytic activities of the aqueous extracts of these plants. The antioxidant activity was evaluated using three in vitro tests: DPPH (2,2-diphenyl-1-picryl-hydrazyl-hydrate) radical scavenging activity, FRAP (ferric reducing antioxidant power assay), and ABTS (2,2'-azino-bis (3-ethylbenzothiazoline-6-sulfonic acid) radical scavenging assay. The antihemolytic activity of plant extracts was evaluated against AAPH (2,2'-azobis(2-amidino-propane) dihydrochloride)-induced erythrocyte hemolysis.
\end{abstract}

Results: Our findings showed that all plant extracts displayed significant antioxidant and antihemolytic effects. In fact, among the studied plant extracts, the highest antioxidant power was recorded in Origanum majorana, based on DPPH $\left(\mathrm{C}_{50}=12.29 \mu \mathrm{g} / \mathrm{mL}\right)$, ABTS $(226.13 \mu \mathrm{mol}$ TE/g DW), and FRAP (477.82 $\mu \mathrm{mol}$ TE/g DW) assays. Moreover, the same plant also showed the best membrane protective effect (269.55\%). Whereas, Ocimum basilicum exhibited the lowest antioxidant activity using DPPH ( $\left(\mathrm{C}_{50}=42.85 \mu \mathrm{g} / \mathrm{mL}\right)$, ABTS $\left(\mathrm{IC}_{50}=226.13 \mu \mathrm{mol} \mathrm{TE} / \mathrm{g} \mathrm{DW}\right)$, and FRAP $\left(\mathrm{IC}_{50}=172.84\right.$ $\mu \mathrm{mol} \mathrm{TE} / \mathrm{g}$ DW) and, thus, the lowest membrane protective effect (182.70\%).

Conclusion: This result supports the use of these plants in folk medicine for preventing and treating many diseases, especially those related to oxidative stress.

Keywords: Antihemolytic activity, Antioxidant activity, Lavandula officinalis, Ocimum basilicum, Origanum majorana

\section{Background}

Plants have been employed in many different forms since the earliest times. They have been used as food additives to improve their organoleptic properties apart from their use in traditional medicine because of their preservative and curative effects [1]. Numerous natural molecules extracted from plants, especially phenolic metabolites, are the main responsible for these biological

\footnotetext{
* Correspondence: abdelbassathmidani@gmail.com

'Biology, Environment and Health Team, Faculty of sciences and Techniques Errachidia, Moulay Ismail University, Zitoune, 11201 Meknes, BP, Morocco ${ }^{2}$ Biochemistry of Natural Product Team, Faculty of sciences and Techniques Errachidia, Moulay Ismail University, Zitoune, 11201 Meknes, BP, Morocco Full list of author information is available at the end of the article
}

activities due to their antioxidant potential [2]. Antioxidants play a key role against oxidative cell damage by inhibiting the formation of free radical species or enhancing their degradation and breakdown [3]. Recently, more and more epidemiological and experimental evidence strongly suggest that excessive free radicals and associated oxidative damage are mediators in several neurodegenerative disorders, cardiovascular problem such as hypertension, liver illnesses, aging, chronic kidney diseases, and cancer [4]. Moreover, in food industry, oxidation is the main cause for the development of unpleasant flavors and other changes that may affect the nutritional quality, the texture, and the appearance of the food, making them unfit for consumption [5]. 
Therefore, antioxidants are beneficial in human body as well as in the food system. Recently, antioxidants from natural sources have attracted an increasing attention because the use of synthetic antioxidants has been suspected to threaten human health [6].

According to Oyebode et al. report [7], 80\% of Asian and African populations employ folk medicine and consult traditional practitioners to meet their primary health care needs because it is more affordable and accessible especially in low- and middle-income countries.

Lavandula officinalis, Origanum majorana, and Ocimum basilicum, known locally as Lkhzama, Mard-doch, and Lahbak, respectively, are among well-known aromatic and medicinal plants in Morocco, because they are widely used to improve the flavor and the taste of tea. Moreover, these plants are utilized to manage many ailments such as liver disease, rheumatism, diabetes, hypercholesterolemia, asthma, pain, kidney disease, cardiac disorders, and digestive problems $[8,9]$.

In the light of the foregoing, the aim of this study is to determine total phenolic, flavonoid, and condensed tannin content, as well as to evaluate the antioxidant and antihemolytic properties of the aqueous extract of three Lamiaceae species.

\section{Methods}

\subsection{Plant material}

Three species of Lamiaceae family locally known as Lkhzama (Lavandula officinalis), Mard-doch (Origanum majorana), and Lahbak (Ocimum basilicum), respectively, were collected in Tinghir Region (southeastern Morocco), during the flowering period April-May 2019. The plants were taxonomically identified and authenticated by $\mathrm{Pr}$ Mohcine Elghazi (Ethnoobothanist at FSTE), and voucher specimen was deposited at the herbarium of the Faculty of Sciences and Techniques Errachidia: Origanum majora (HMOm185); Lavandula officinalis (HMLo 199); Ocimum basilicum (HMOb 205). The plant materials were dried and stored at room temperature $\left(25^{\circ} \mathrm{C}\right)$ in the dark for extraction.

\subsection{Preparation of plant extracts}

The aqueous extracts were obtained according to the method of Bouhlali et al. [10] with slight modifications. In brief, $30 \mathrm{~g}$ of plant material was extracted in $500 \mathrm{~mL}$ of distilled water for $12 \mathrm{~h}$ at $35{ }^{\circ} \mathrm{C}$ with an orbital shaking incubator. Then, the mixture was filtered and the filtrate was concentrated under reduced pressure at $40{ }^{\circ} \mathrm{C}$ until total evaporation of the water, by a rotary evaporator. The crude extracts were stored at $-20{ }^{\circ} \mathrm{C}$ in dark glass bottles until use. The extracts were dissolved in a known dilution in distilled water in order to measure the phenol, flavonoid, condensed tannin content, and their antioxidant properties.

\subsection{Measurement of total phenolic compounds}

The total phenolic content of plant extracts was determined following the method of Hmidani et al. [11]. In brief, $100 \mu \mathrm{L}$ of the extract was added to $500 \mu \mathrm{L}$ of a $1 /$ 10 dilution of the Folin-Ciocalteau reagent in distilled water, and then $400 \mu \mathrm{L}$ of sodium carbonate solution $(7.5 \% \mathrm{w} / \mathrm{v})$ was added. The mixture was left for $60 \mathrm{~min}$ at room temperature, where the absorbance was measured at $765 \mathrm{~nm}$. Gallic acid was used to prepare the calibration curve. Total phenolic compounds were reported as milligram gallic acid equivalent (GAE) per gram of plant dry weight (DW).

\subsection{Measurement of flavonoid content}

The total flavonoid content of plant was determined by the method of Kim et al. [12]. One milliliter of plant extract was mixed with $4 \mathrm{~mL}$ of distilled water. Then, 0.3 $\mathrm{mL}$ of sodium nitrite solution (5\%) was added, followed by $0.3 \mathrm{~mL}$ aluminum chloride solution (10\%). Test tubes were incubated for $5 \mathrm{~min}$ at ambient temperature, and then $2 \mathrm{~mL}$ of sodium hydroxide $(1 \mathrm{M})$ was added to the mixture and then the final volume was made up to $10 \mathrm{~mL}$ with distilled water. The mixture was thoroughly vortexed and the absorbance was determined at $510 \mathrm{~nm}$. Measurements were calibrated to a standard curve of prepared rutin solution, and the results were expressed as milligram rutin equivalent (RE) per gram dry weight (DW).

\subsection{Measurement of total condensed tannins}

The total condensed tannins were measured according to the method modified by Heimler et al. [13]. In brief, $400 \mu \mathrm{L}$ of the plant extract was added in $3 \mathrm{~mL}$ of methanolic solution of vanillin (4\%) and $1.5 \mathrm{~mL}$ of concentrated hydrochloric acid. The mixture was allowed to incubate at room temperature for $15 \mathrm{~min}$ and the absorbance was recorded at $500 \mathrm{~nm}$. A calibration curve of catechin was prepared, and the results were expressed as mg CE (Catechin Equivalent)/g DW (plant dry weight).

\subsection{ABTS radical scavenging assay}

The ABTS radical scavenging was evaluated in accordance with the method of Re et al. [14]. The ABTS radical cations $(\mathrm{ABTS}+)$ were generated by reacting aqueous solution of ABTS (7 mM) with an aqueous solution of potassium persulphate $(2.45 \mathrm{mM})$. Before the use of the mixture, it was allowed to stand in the dark at room temperature for $12-16 \mathrm{~h}$, and then diluted with distilled water to get an absorbance of $0.700 \pm 0.005$ at $734 \mathrm{~nm}$. Thirty microliters of the sample added to $3 \mathrm{~mL}$ of the ABTS radical solution was incubated at room temperature for $6 \mathrm{~min}$ and the absorbance at $734 \mathrm{~nm}$ was calculated immediately. A standard curve was obtained using an aqueous solution of Trolox. The total 
antioxidants were expressed as grams of Trolox Equivalent (TE) per gram of plant dry weight (DW).

\subsection{Ferric reducing antioxidant power assay}

The ferric reducing ability of plant extract was assessed following the procedure of Benzie and Strain method [15]. In brief, the FRAP reagent was obtained using a mixture of $50 \mathrm{~mL}$ acetate buffer $(0.3 \mathrm{M})$ at $\mathrm{pH} 3.6,5 \mathrm{ml}$ tripydyltriazine (TPTZ) solution dissolved in $\mathrm{HCl}(40 \mathrm{mM})$ and 5 $\mathrm{ml}$ ferric chloride $(\mathrm{FeCl} 3)$ solution $(20 \mathrm{mM})$. Two milliliters of the freshly prepared FRAP reagent has been added to $10 \mu \mathrm{L}$ of plant extract. The absorbance was calculated at $593 \mathrm{~nm}$ against the blank after $10 \mathrm{~min}$ at room temperature. The standard curve was plotted using Trolox. The result was reported as Trolox equivalent (TE) in milligram per gram of plant dry weight (DW).

\subsection{DPPH radical scavenging power}

As described by Blois method with slight modifications [16], the plants were evaluated for their abilities to scavenge the DPPH radical. Brief, $100 \mu \mathrm{L}$ of plant extract, at different concentrations, was added in $1.9 \mathrm{~mL}$ of methanolic DPPH (0.3 mM). The absorbance was measured at 517 with a spectrophotometer after incubation of mixture at room temperature for $20 \mathrm{~min}$ in the dark. The $\mathrm{IC}_{50}$ values were calculated as the concentration providing $50 \%$ inhibition of the DPPH radical based on the plotted graph of scavenging capacity against sample concentrations.

\subsection{The protective effect of plant extracts against AAPH induced erythrocyte oxidative hemolysis}

The antihemolytic activity caused by a peroxyl radical initiator, AAPH, was determined by the method reported by Blache and Prost [17] with slight modifications. Two hundred microliters of rabbit blood taken from heparin bulbs has been mixed with $10 \mu \mathrm{L}$ of plant extract. Then $600 \mu \mathrm{L}$ of AAPH (10\%) was added. Incubation of the mixture was carried out at $37{ }^{\circ} \mathrm{C}$. Absorbance of the mixture was recorded at $450 \mathrm{~nm}$ every 5 min. Plant extract was substituted with Trolox and saline water $(0.9 \% \mathrm{NaCl})$ in the positive and negative controls, respectively. The protective effects of the plant extract on free radical-induced hemolysis of erythrocytes were estimated on the basis of the time needed for $50 \%$ of hemolysis, the percentage of hemolysis induced by $600 \mu \mathrm{L}$ AAPH (10\%) was taken here as $100 \%$ hemolysis.

\subsection{Statistical analysis}

Statistical analysis was carried out with StatView 5.0 software. Results were expressed as the average of the repetitions of all experiments $\pm \mathrm{SE}$ (standard error). Analysis of variance (ANOVA) and post hoc Bonferroni tests were utilized to compare the experimental groups.
The Pearson correlation coefficient $(r)$ has been used for measuring the correlation between two variables. Differences at $p<0.05$ were reported as significant.

\section{Results}

\subsection{Phenolic content}

\subsubsection{Total phenolic content}

Standard calibration curve gallic acid was used to evaluate the total phenolic content in the aqueous extracts of studied plants. Results are shown in Table 1, and it has been noted that all studied plant extracts exhibited a large amount of phenolic content, where the amount of polyphenols is varied in different tested plants and ranged from $52.35 \pm 2.15 \mathrm{mg}$ GAE/g DW in Origanum majorana to $27.82 \pm 1.53 \mathrm{mg}$ GAE/g DW in Ocimum basilicum.

\subsubsection{Total flavonoid content}

Table 1 reports total flavonoid content data in milligram rutin equivalent per gram of dry weight (mg RE/g DW). The flavonoid content in the selected species ranged from 24.41 (Origanum majorana) to $11.94 \mathrm{mg}$ RE/g DW (Ocimum basilicum).

\subsubsection{Total condensed tannins}

The total condensed tannin content of selected plants of Lamiaceae is shown in Table 1 . Where the tannin content was found highest in Origanum majorana (8.73 \pm $0.91 \mathrm{mg} \mathrm{CE} / \mathrm{g} \mathrm{DW}$ ) and lowest in Lavandula officinalis $(3.04 \pm 0.82 \mathrm{mg} \mathrm{CE} / \mathrm{g} \mathrm{DW})$.

\subsection{In vitro antioxidant activity}

In vitro antioxidant power of plants was assessed using three different tests: DPPH, ABTS, and FRAP assays. The findings from these assays are detailed below.

\subsubsection{DPPH radical scavenging power}

The in vitro antioxidant capacity of samples is presented in Table 1. Findings are expressed as $\mathrm{IC}_{50}$. In this activity, Origanum majorana $(12.29 \mu \mathrm{g} / \mathrm{mL})$ demonstrated the highest antioxidant capacity, followed by Lavandula officinalis (22.54 $\mu \mathrm{g} / \mathrm{mL})$ and Ocimum basilicum $(42.85 \mu \mathrm{g} / \mathrm{mL})$.

\subsubsection{ABTS radical scavenging assay}

Table 1 shows the scavenging effects of extracts on ABTS radical. The highest activity has been recorded in Origanum majorana (226.13 $\mu \mathrm{mol} \mathrm{TE} / \mathrm{g} \mathrm{DW})$, followed by Lavandula officinalis $(112.94 \pm 6.49 \mu \mathrm{mol}$ TE/g DW), and Ocimum basilicum $(91.49 \pm 5.84 \mu \mathrm{mol}$ TE/g DW).

\subsubsection{Ferric reducing antioxidant power assay}

As summarized in Table 1, the best reducing power based on FRAP assay was shown in Origanum majorana (477.82 $\mu \mathrm{mol} \mathrm{TE} / \mathrm{g} \mathrm{DW})$, followed by Lavandula 
Table 1 Phenolic, flavonoid, and tannin content and in vitro antioxidant activities of three Lamiaceae species aqueous extracts

\begin{tabular}{lllllll}
\hline & Polyphenols $\mathbf{( m g ~ G A E / g ~ D W ) ~}$ & $\begin{array}{l}\text { Flavonoids } \\
(\mathbf{m g ~ R E} / \mathbf{g ~ D W})\end{array}$ & $\begin{array}{l}\text { Tannins } \\
(\mathbf{m g ~ C E} / \mathbf{g ~ D W})\end{array}$ & $\begin{array}{l}\text { DPPH } \\
\left(\mathbf{I C}_{\mathbf{5 0}} \text { in } \boldsymbol{\mu g} / \mathbf{m l}\right)\end{array}$ & $\begin{array}{l}\text { ABTS } \\
(\boldsymbol{\mu m o l ~ T E / g ~ D W ) ~}\end{array}$ & $\begin{array}{l}\text { FRAP } \\
(\boldsymbol{\mu m o l} \text { TE/g DW) }\end{array}$ \\
\hline Lavandula officinalis & $20.62 \pm 1.87^{\mathrm{a}}$ & $13.84 \pm 3.16^{\mathrm{a}}$ & $3.04 \pm 0.82^{\mathrm{a}}$ & $22.54 \pm 0.84^{\mathrm{a}}$ & $112.94 \pm 6.49^{\mathrm{a}}$ & $226.82 \pm 7.9^{\mathrm{a}}$ \\
Origanum majorana & $52.35 \pm 2.15^{\mathrm{b}}$ & $24.41 \pm 4.03^{\mathrm{b}}$ & $8.73 \pm 0.91^{\mathrm{b}}$ & $12.29 \pm 1.06^{\mathrm{b}}$ & $226.13 \pm 5.42^{\mathrm{b}}$ & $477.82 \pm 8.06^{\mathrm{b}}$ \\
Ocimum basilicum & $27.82 \pm 1.53^{\mathrm{c}}$ & $11.94 \pm 4.82^{\mathrm{a}}$ & $5.87 \pm 1.09^{\mathrm{c}}$ & $42.85 \pm 1.32^{\mathrm{c}}$ & $91 \pm 5.84^{\mathrm{c}}$ & $172.84 \pm 6.18^{\mathrm{c}}$ \\
\hline
\end{tabular}

Data are expressed as the means of quadruplicate $(n=4) \pm(\mathrm{SE})$. Within each column, values with different superscript are significantly different $(p<0.05)$ ABTS 2 2-azinobis (3 ethylbenzothiazoline 6-sulfonic acid), DPPH 1 1-Diphenyl-2-picrylhydrazyl, FRAP Ferric reducing antioxidant power, GAE Gallic acid equivalent, RE Rutin equivalent, TE Trolox equivalent, CE Catechin equivalent

officinalis (226.82 $\mu \mathrm{mol} \mathrm{TE} / \mathrm{g} \mathrm{DW})$ and Ocimum basilicum (172.84 $\mu \mathrm{mol} \mathrm{TE} / \mathrm{g} \mathrm{DW})$.

\subsection{In vitro antihemolytic activity}

The in vitro antihemolytic activity of plant extracts is displayed in Tables 2 and 3. Indeed, from Table 2, the Origanum majorana extract exhibited the best protective effect against AAPH-induced oxidative erythrocytes hemolysis (269.55\%), followed by Lavandula officinalis (221.72\%) and Ocimum basilicum (182.70\%), while the protect effect of Trolox (1\%) was in order to (120, 82\%). Moreover, as illustrated in Table 3, the greatest stabilizing effect was observed in Origanum majorana extract (105.54\%), followed by Ocimum basilicum (69.23\%), and Lavandula officinalis (64.55\%).

\section{Discussion}

Plants are an interesting source of bioactive natural compounds such as flavonoids, ascorbic acid, and phenolic acids [18]. Thanks to their beneficial effects on human health and their several biological activities including antioxidant and antihemolytic capacities, many scientific researchers have been focusing on the study of phenolic acids $[19,20]$. In this regard, the purpose of this study was to assess the phenolic content, antioxidant, and antihemolytic properties of the aqueous extracts of three plants from the Lamiaceae family, commonly used in Moroccan folk medicine. Interestingly, our data demonstrate that all selected plant extracts contain an appreciable level of total phenolic content, flavonoid, and total condensed tannins, and the best amount was recorded in Origanum majorana, followed by Lavandula officinalis and, then, Ocimum basilicum. Our results are higher than those reported by Méabed et al. [21] who have found that total phenolic content in Origanum majorana from Egypt was $9.2 \mathrm{mg}$ GAE/g DW. However, Surveswaran and co-workers [22] reported that the amount of total phenolic content in Ocimum basilicum (26.3 mg GAE/g DW) was slightly higher compared to this found in the current study. In the same way, Spiridon et al. [23] mentioned a greater level of polyphenols in Lavandula angustifolia (50.6 mg GAE/g DW). In addition, this investigation confirms the previous results found in several plants, mainly those from Lamiaceae family. In this respect, khomdram and Singh (Khomdram and Singh, 2011) indicate that total phenolic content in eight plants (Lamiaceae family) is ranged between 46.28 and $23.80 \mathrm{mg} \mathrm{CE} / \mathrm{g} \mathrm{DW}$. Concerning other classes of polyphenols, a remarkable amount of flavonoid content also recorded in selected plant species. In this respect, Méabed et al. [21] showed that Egyptian Origanum majorana contains appreciable total flavonoid content $(57.3 \mathrm{mg}$ quercetin equivalent (QE)/g DW). Other scientific researchers confirm the notable amount of flavonoids in Ocimum basilicum and Lavandula species [24, 25]. Moreover, the tested plants also possess a significant amount of condensed tannins. This result is in agreement with other researches which confirmed the presence of condensed tannins in plant extracts [26]. Indeed, Kpètèhoto et al. [27] demonstrated that the level of condensed tannins in Ocimum gratissimum linn harvested in southern Benin (2017) was in the

Table 2 Antihemolytic activity of aqueous extracts of three Lamiaceae species against AAPH induced hemolysis

\begin{tabular}{llc}
\hline & Half-time of hemolysis (min) & Protective effect (\%) \\
\hline Control & $142.48^{* a}+4.62$ & $99.71^{*}+1.33$ \\
AAPH + blood & $71.34^{\mathrm{b}}+4.06$ & - \\
AAPH + blood + (L. officinalis) extract & $229.52^{* \mathrm{c}}+4.87$ & $221.72^{*}+1.55$ \\
AAPH + blood + (O. majorana ) extract & $263.64^{* \mathrm{~d}}+5.43$ & $269.55^{*}+2.22$ \\
AAPH + blood + (O. basilicum ) extract & $201.68^{*}+5.17$ & $182.70^{*}+2.13$ \\
AAPH + trolox (1\%) & $157.54^{* f}+5.24$ & $120.82^{*}+2.17$ \\
\hline
\end{tabular}

Values in average $(n=6) \pm$ SE vs positive control (AAPH + blood). Within each column, values with different superscript (a-f) are significantly different $(p<0.05)$ AAPH 2,2'-azobis-(2 amidinopropane)

${ }^{*} p \leq 0.001$ 
Table 3 Antihemolytic activity and the membrane-stabilizing effect induced by plant extracts

\begin{tabular}{lll}
\hline & half-time of hemolysis (min) & Stabilizing effect (\%) \\
\hline Control & $142.48^{\mathrm{a}}+4.62$ & $100+1.33$ \\
Lavandula officinalis & $234.46^{* \mathrm{~b}}+4.36$ & $64.55^{*}+1.18$ \\
Origanum majorana & $292.86^{* \mathrm{c}}+5.63$ & $105.544^{*}+1.58$ \\
Ocimum basilicum & $241.12^{* \mathrm{~d}}+6.72$ & $69.23^{*}+1.80$ \\
\hline
\end{tabular}

Values in average $(n=6) \pm$ SE (standard error) vs control. Values with different superscript (a-d) are significantly different $(p<0.05)$

AAPH 2,2'-azobis-(2 amidinopropane)

${ }^{*} p \leq 0.001$

order of $8.6 \mathrm{mg}$ catechin equivalent/100 mg. Furthermore, based on a study on some Tunisian medicinal plants carried out by Neffati and his co-workers [28], it seems that the majority of these plants show low condensed tannins, except for Rhus tripartitum and Periploca laevigat. The difference found in phenolic compounds could be attributed in part to the genetic diversity, plant part, geographical distribution, phytochemical content [29].

Since the methods of antioxidant activities differ in their mechanisms of action and offer more insights about the sample's antioxidant potential, tested plants, in this study, have been evaluated using three antioxidant methods : DPPH, ABTS, and FRAP assays.

The DPPH method consists of measuring the capacity of an antioxidant substance to reduce the DPPH• radicals to the corresponding hydrazine, and simultaneously changing its color from violet to yellow, with concomitant decrease in absorbance at $517 \mathrm{~nm}$ [30]. Data are expressed as $\mathrm{IC}_{50}$, defined as the substrate concentration causing a loss of $50 \%$ of DPPH activity (Table 1). A lower $\mathrm{IC}_{50}$ reflects a higher antioxidant effect. In the present investigation, all plant extracts exhibit considerable antioxidant activities based on DPPH method in a concentration-dependent manner. Thus, Origanum majorana extract $(12.29 \mu \mathrm{g} / \mathrm{mL})$ displayed the highest antioxidant capacity. The ABTS method is largely accepted to evaluate the antioxidant capacity of food extracts, natural products, and pure compounds [31]. This assay measures the potential of the antioxidant to scavenge the radical (ABTS+•) produced in the aqueous phase at 734 $\mathrm{nm}$ [32]. In addition, the decolorization of ABTS radical cation reflects the capacity of the plant extracts to donate electrons or hydrogen atoms and to deactivate these radical species [32]. The finding recorded during this investigation demonstrated that overall extracts exhibit potent abilities to quench the free radical ABTS. The antioxidant potential of plant extracts was also estimated for their ability to reduce the ferric tripyridyltriazine complex to the colored ferrous tripyridyltriazine [33]. Data from the present work display a significant reducing power in all plant extracts using FRAP assay. The findings of this paper conform to the previous reports which have demonstrated the interesting potential antioxidant capacity of the species studied here. In fact, Petrovic and his collaborators [34] indicated that the antioxidant capacities of Serbian Lavandula officinalis through DPPH, ABTS, and FRAP were $4.35,10.35$, and $15.53 \mathrm{mmol}$ Trolox equivalent/L, respectively. Furthermore, Duletić-Laušević and coauthors [35] examined the ethanolic and the aqueous extracts of Origanum majorana L. originating from Serbia, Greece, Egypt, and Libya. They showed that the highest antioxidant ability was manifested by Serbian aqueous extracts based on DPPH $\left(\mathrm{IC}_{50}=28.25 \mathrm{mg} / \mathrm{mL}\right), \mathrm{ABTS}$ (2.06 $\mathrm{mg}$ ascorbic acid equivalent $/ \mathrm{mL}$ ), and FRAP (826.45 umol Fe (II)/g). Moreover, in a recent study, Rezzoug et al. [36] measured the antioxidant activity of Algerian Ocimum basilicum ethanolic extract using DPPH, ABTS, and FRAP assays. The extract displayed moderate activities against $\mathrm{DPPH}$ radical $\left(\mathrm{IC}_{50}=0.629\right.$ $\mathrm{mg} / \mathrm{mL})$, ABTS radical $\left(\mathrm{IC}_{50}=0.629 \mathrm{mg} / \mathrm{mL}\right)$, and a considerable reducing power of ferric complex $(3657 \mathrm{mg}$ ascorbic acid equivalent $/ \mathrm{mL}$ ).

To correlate these results with the different methods, a linear regression analysis was carried out $\left(r^{2}\right.$, Table 4$)$. Accordingly, a significant correlation was found between phenolic compounds and the antioxidant capacities assessed using DPPH, ABTS, and FRAP methods. This high correlation suggests that the antioxidant power found in the studied extracts could possibly be due to their phenolic content $\left(r^{2}\right.$ polyphenols/FRAP $=0.86 ; r_{\text {polyphe- }}^{2}$ nols/DPPH $=0.87)$. The present data were supported by several earlier reports that highlight on the most important relationship between antioxidant activities and phenolic content [37-39].

Erythrocytes are very sensitive cells to oxidative stress. This sensitivity is related to their rich membrane lipid composition of polyunsaturated fatty acids, the constant interactions with oxygen, and the production of ROS by activated inflammation cells [40,41]. Additionally, the presence of hemoglobin in large quantities also exposes red blood cells to high levels of auto-oxidation [42]. Therefore, hemolysis is widely employed as an important indicator of free radical damage affecting the membrane of erythrocytes [43]. On the other hand, the antioxidant 
Table 4 Correlation between ABTS, FRAP, DPPH, AAPH, polyphenols, flavonoids, and tannins content

\begin{tabular}{lllllll}
\hline & Polyphenols & Flavonoids & Tannins & DPPH & ABTS & FRAP \\
\hline Polyphenols & 1 & & & & & \\
Flavonoids & 0.88 & 1 & & & & \\
Tannins & 0.91 & 0.62 & 1 & & & \\
DPPH & 0.36 & 0.62 & 0.11 & 1 & & 1 \\
ABTS & 0.87 & 0.99 & 0.61 & 0.71 & 0.999 & 1 \\
FRAP & 0.86 & 0.99 & 0.59 & 0.73 & 0.90 & 0.91 \\
AAPH & 0.60 & 0.90 & 0.30 & 0.94 & 0.90 & 1 \\
\hline
\end{tabular}

Pearson correlation coefficient $\left(r^{2}\right)$ was used to measure the association between two variables. ABTS 2 2-azinobis (3-ethylbenzothiazoline 6-sulfonic acid), DPPH 1 1 Diphenyl-2-picrylhydrazyl, FRAP Ferric reducing antioxidant power, TE Trolox equivalent, AAPH 2 2'-azobis-(2-amidinopropane)

compounds are known to have the ability to scavenge free radicals and protect the cells against hemolysis induced by oxidative stress. In this study, an assessment was performed on the ability of plant extracts to protect red blood cells (RBCs) from oxidative damage caused by AAPH-induced hemolysis. Our data, expressed as the half-hemolysis time $\left(\mathrm{HT}_{50 \%}\right.$, which is the time required for hemolysis of $50 \%$ of erythrocytes) and the percentage of protective effect on erythrocyte membrane, indicated that all studied plant extracts significantly protected the membrane of the red blood cells from hemolysis better than Trolox (1\%), used as a standard antioxidant. These results clearly demonstrated that the selected plant extracts were able to scavenge AAPH-derived peroxyl radicals, thereby protecting erythrocyte membrane. Furthermore, tested extracts induced a significant increase of half-hemolysis time compared to the control containing only blood. The finding clearly demonstrated the important stabilizing effect of selected plants on the erythrocyte membrane.

The analysis of linear correlation displayed a significant interaction between hemolytic inhibition activities (AAPH) and polyphenols content $\left(r^{2}=0.60\right)$, flavonoids content $\left(r^{2}=0.90\right)$, while a weak correlation was detected for condensed tannins $\left(r^{2}=0.30\right)$. On the basis of these results, some of this activity seems to be explained by the presence of polyphenols in plant extracts, especially flavonoids. Our results are also in the same line with previous investigations that have proven the remarkable antihemolytic activity of several plant extracts, and the capacity of the phenolic content to protect erythrocytes from oxidative stress or to increase their resistance to oxidativeinduced damage. Indeed, in a recent scientific work, Deruich et al. [44] assessed the protective effect of erythrocyte membrane against AAPH-induced hemolysis of three Apiaceae plants from Morocco and, thus, they concluded that Petroselinum crispum manifested the highest protective effect $\left(\mathrm{HT}_{50 \%}=273.64 \mathrm{~min}\right)$ and Apium graveolens recorded the lowest effect $\left(\mathrm{HT}_{50 \%}=194.71 \mathrm{~min}\right)$. Moreover, Bhat and his collaborators [45] displayed that an alcoholic extract of Caralluma quadrangula from the Northwestern region of Saudi Arabia exhibited an inhibition of red blood cell lysis close to $90 \%$ at the highest concentration 2000 $\mu \mathrm{g} / \mathrm{mL}$.

\section{Conclusion}

The present scientific research indicates that all studied plant extracts possess considerable antihemolytic and antioxidant capacities and, thus, the Origanum majorana species has shown the best results. These results confirm the use of these plants in popular medicine for the prevention and treatment of many diseases, especially those related to oxidative stress. In addition, more research is needed to identify and characterize the bioactive compounds responsible for these observed biological activities.

\section{Abbreviations}

RE: Rutin equivalent; AAPH: 2,2'-azobis(2-amidino-propane) dihydrochloride; CE: Catechin equivalent; DPPH: 2,2-diphenyl-1-picryl-hydrazyl-hydrate; DW: Plant dry weight; FRAP: Ferric reducing antioxidant power; GAE: Gallic acid equivalent; $\mathrm{I}_{50}$ : Half inhibition concentration; TE: Trolox equivalent; ABTS: 2,2'-azino-bis (3-ethylbenzothiazoline-6-sulfonic acid); $\mathrm{HT}_{50}$ : Halfhemolysis time

\section{Acknowledgements}

The authors would like to thank for Pr. Najat Taghlaoui and Dr. Amssayef Ayoub for their assistance and valuable guidance.

\section{Authors' contributions}

We declare that this work was done by the authors named in this article. CA, $M B$, and EDB conceived and designed the study. $A H$ and $M A$ carried out the laboratory works and collected and analyzed the data and writing of the manuscript. AH, MA, and TK have participated in manuscript revision. All authors read and approved the final manuscript.

\section{Funding}

None.

Availability of data and materials

The data used to support the findings of this study are available from the corresponding author upon request.

\section{Declarations}

Ethics approval and consent to participate

No human was used in this research. All animal research procedures were followed in accordance with to the ethical committee (Faculty of Sciences and Techniques Errachidia, Morocco). 


\section{Consent for publication}

Not applicable.

\section{Competing interests}

The authors declare no competing interests.

\section{Author details}

${ }^{1}$ Biology, Environment and Health Team, Faculty of sciences and Techniques Errachidia, Moulay Ismail University, Zitoune, 11201 Meknes, BP, Morocco. ${ }^{2}$ Biochemistry of Natural Product Team, Faculty of sciences and Techniques Errachidia, Moulay Ismail University, Zitoune, 11201 Meknes, BP, Morocco. ${ }^{3}$ National Institute of Agronomic Research Regional Center of Errachidia, Errachidia, Morocco. ${ }^{4}$ Endocrine pharmacology and physiology of nutrition Team. Faculty of sciences and Techniques Errachidia, Moulay Ismail University, Zitoune, 11201 Meknes, BP, Morocco.

Received: 8 April 2020 Accepted: 3 April 2021

Published online: 17 April 2021

\section{References}

1. Romano B, Lucariello G, Capasso R (2021) Topical collection 'pharmacology of medicinal plants'. Multidisciplinary Digital Publishing Institute

2. do Nascimento et al (2020) Bioactive natural compounds and antioxidant activity of essential oils from spice plants: new findings and potential applications. Biomolecules 10(7):988

3. Alkadi H (2020) A review on free radicals and antioxidants. Infect DisordDrug Targets 20(1):16-26

4. Biswas SK (2016) Does the interdependence between oxidative stress and inflammation explain the antioxidant paradox? Oxid Med Cell Long 2016:9. https://doi.org/10.1155/2016/569893

5. Li Y, Zheng Y, Zhang Y, Xu J, Gao G (2018) Antioxidant activity of coconut (Cocos nucifera L.) protein fractions. Molecules 23(3):707

6. Zheng Y, Li Y, Zhang Y (2017) Purification and identification of antioxidative peptides of palm kernel expeller glutelin-1 hydrolysates. RSC Adv 7(85): 54196-54202. https://doi.org/10.1039/C7RA11657H

7. Oyebode O, Kandala N-B, Chilton PJ, Lilford RJ (2016) Use of traditional medicine in middle-income countries: a WHO-SAGE study. Health Policy Plan 31(8):984-991. https://doi.org/10.1093/heapol/czw022

8. El-Gharbaoui A, Benítez G, González-Tejero MR, Molero-Mesa J, Merzouki A (2017) Comparison of Lamiaceae medicinal uses in eastern Morocco and eastern Andalusia and in Ibn al-Baytar's compendium of simple medicaments (13th century CE). J Ethnopharmacol 202:208-224. https://doi. org/10.1016/j.jep.2017.03.014

9. Eddouks M, Maghrani M, Lemhadri A, Ouahidi M, Jouad H (2002) Ethnopharmacological Sur v ey of medicinal plants used for the treatment of diabetes mellitus, hypertension and cardiac diseases in the south-east region of Morocco ( Tafilalet ). J Ethnopharmacol 82:97-103

10. Bouhlali T, Alem C, Ennassir J, Benlyas M, Nait A, Filali Y (2015) Phytochemical compositions and antioxidant capacity of three date (Phoenix dactylifera L) seeds varieties grown in the south East Morocco. J Saudi Soc Agric Sci 16:350-357. https://doi.org/10.1016/j.jssas.2015.11.002

11. Hmidani A, Khouya T, Ramchoun M, Filali-zegzouti Y, Benlyas M, Alem C (2019) Effect of extraction methods on antioxidant and anticoagulant activities of Thymus atlanticus aerial part. Sci Afr 5:e00143. https://doi.org/1 0.1016/j.sciaf.2019.e00143

12. Kim D-O, Jeong SW, Lee CY (2003) Antioxidant capacity of phenolic phytochemicals from various cultivars of plums. Food Chem 81(3):321-326 https://doi.org/10.1016/S0308-8146(02)00423-5

13. Heimler D, Vignolini P, Dini MG, Vincieri FF, Romani A (2006) Antiradical activity and polyphenol composition of local Brassicaceae edible varieties. Food Chem 99(3):464-469

14. Re R, Pellegrini N, Proteggente A, Pannala A, Yang M, Rice-Evans C (1999) Antioxidant activity applying an improved ABTS radical cation decolorization assay. Free Radic Biol Med 26(9-10):1231-1237. https://doi. org/10.1016/S0891-5849(98)00315-3

15. Benzie IFF, Strain JJ (1999) [2] ferric reducing/antioxidant power assay: direct measure of total antioxidant activity of biological fluids and modified version for simultaneous measurement of total antioxidant power and ascorbic acid concentration. In: Methods in enzymology, vol 299. Elsevier, pp $15-27$
16. Blois MS (1958) Antioxidant determinations by the use of a stable free radical. Nature 181(4617):1199

17. Blache D, Prost M (1992) Free radical attack- biological test for human resistance capability. In: A lunar-based chemical analysis laboratory(a 9317426 04-51). A. Deepak Publishing, Hampton, pp 82-98

18. (2020) Plant extracts as a natural source of bioactive compounds and potential remedy for the treatment of certain skin diseases. Curr Pharm Des 26(24):2859-2875. https://doi.org/10.2174/1381612826666200417160049

19. Potì F, Santi D, Spaggiari G, Zimetti F, Zanotti I (2019) Polyphenol health effects on cardiovascular and neurodegenerative disorders: a review and meta-analysis. Int J Mol Sci 20(2):351

20. Sun L, Miao M (2019) Dietary polyphenols modulate starch digestion and glycaemic level: a review. In: Critical reviews in food science and nutrition, pp 1-15

21. Méabed EMH, El-Sayed NM, Abou-Sreea AIB, Roby MHH (2018) Chemical analysis of aqueous extracts of Origanum majorana and Foeniculum vulgare and their efficacy on Blastocystis spp. cysts. Phytomedicine 43:158-163. https://doi.org/10.1016/j.phymed.2018.04.017

22. Surveswaran S, Cai Y-Z, Corke H, Sun M (2007) Systematic evaluation of natural phenolic antioxidants from 133 Indian medicinal plants. Food Chem 102(3):938-953. https://doi.org/10.1016/j.foodchem.2006.06.033

23. Spiridon I, Colceru S, Anghel N, Teaca CA, Bodirlau R, Armatu A (2011) Antioxidant capacity and total phenolic contents of oregano (Origanum vulgare), lavender (Lavandula angustifolia) and lemon balm (Melissa officinalis) from Romania. Nat Prod Res 25(17):1657-1661. https://doi.org/1 $0.1080 / 14786419.2010 .521502$

24. Gird C-E, Costea T, Nencu I, Dutu LE, Popescu L, Balaci TD (2015) Comparative pharmacognostic analysis of romanian Ocimum Basilicum L. and O. Basilicum Var. Purpurascens Benth. Aerial parts. Farmacia 63(6):840-844

25. Adaszyńska-Skwirzyńska M, Dzięcioł M (2017) Comparison of phenolic acids and flavonoids contents in various cultivars and parts of common lavender (Lavandula angustifolia) derived from Poland. Nat Prod Res 31(21):25752580. https://doi.org/10.1080/14786419.2017.1320792

26. Sankhalkar S, Vernekar V (2016) Quantitative and qualitative analysis of phenolic and flavonoid content in Moringa oleifera lam and Ocimum tenuiflorum L. Pharm Res 8(1):16

27. Kpètèhoto HW et al (2019) Phytochemical analysis and antioxidant potential of Ocimum gratissimum Linn (Lamiaceae) commonly consumed in the Republic of Benin. J Appl Biol Biotechnol 7:75-83

28. Neffati N, Aloui Z, Karoui H, Guizani I, Boussaid M, Zaouali Y (2017) Phytochemical composition and antioxidant activity of medicinal plants collected from the Tunisian flora. Nat Prod Res 31(13):1583-1588. https:// doi.org/10.1080/14786419.2017.1280490

29. Tripodi P, Cardi T, Bianchi G, Migliori CA, Schiavi M, Rotino GL, Lo Scalzo R (2018) Genetic and environmental factors underlying variation in yield performance and bioactive compound content of hot pepper varieties (Capsicum annuum) cultivated in two contrasting Italian locations. Eur Food Res Technol 244(9):1555-1567. https://doi.org/10.1007/s00217-018-3069-5

30. Zadra A, Robert G (2012) Dream recall frequency: impact of prospective measures and motivational factors. Conscious Cogn 21(4):1695-1702. https://doi.org/10.1016/j.concog.2012.08.011

31. Ilyasov IR, Beloborodov VL, Selivanova IA, Terekhov RP (2020) ABTS/PP decolorization assay of antioxidant capacity reaction pathways. Int J Mol Sci 21(3):1131

32. Sasikumar JM, Maheshu V, Aseervatham G, Darsini D (2010) In vitro antioxidant activity of Hedyotis corymbosa (L.) lam. Aerial parts

33. Johnson RJ, Nakagawa T, Jalal D, Sánchez-Lozada LG, Kang D-H, Ritz E (2013) Uric acid and chronic kidney disease: which is chasing which? Nephrol Dial Transplant 28(9):2221-2228. https://doi.org/10.1093/ndt/gft029

34. Petrovic M, Suznjevic D, Pastor F, Veljovic M, Pezo L, Antic M, Gorjanovic S (2016) Antioxidant capacity determination of complex samples and individual phenolics-multilateral approach. Comb Chem High Throughput Screen 19(1):58-65. https://doi.org/10.2174/1386207318666151102094227

35. Duletić-Laušević S et al (2018) Antineurodegenerative, antioxidant and antibacterial activities and phenolic components of Origanum majorana L. (Lamiaceae) extracts. J Appl Bot Food Qual 91:126-134

36. Rezzoug $\mathrm{M}$ et al (2019) Chemical composition and bioactivity of essential oils and Ethanolic extracts of Ocimum basilicum L. and Thymus algeriensis Boiss. \& Reut. From the Algerian Saharan atlas. BMC Complement Altern Med 19(1):1-10

37. Peiretti PG et al (2019) Phenolic composition and antioxidant activities of soybean (Glycine max (L.) Merr.) plant during growth cycle. Agronomy 9(3):153 
38. Derakhshan Z, Ferrante M, Tadi M, Ansari F, Heydari A, Hosseini MS, Conti GO, Sadrabad EK (2018) Antioxidant activity and total phenolic content of ethanolic extract of pomegranate peels, juice and seeds. Food Chem Toxicol 114:108-111. https://doi.org/10.1016/j.fct.2018.02.023

39. Granato D, Shahidi F, Wrolstad R, Kilmartin P, Melton LD, Hidalgo FJ, Miyashita K, Camp J, Alasalvar C, Ismail AB, Elmore S, Birch GG,

Charalampopoulos D, Astley SB, Pegg R, Zhou P, Finglas P (2018) Antioxidant activity, total phenolics and flavonoids contents: should we ban in vitro screening methods? Food Chem 264:471-475. https://doi.org/10.101 6/j.foodchem.2018.04.012

40. Nabavi SF, Nabavi SM, Setzer WN, Nabavi SA, Nabavi SA, Ebrahimzadeh MA (2013) Antioxidant and antihemolytic activity of lipid-soluble bioactive substances in avocado fruits. Fruits 68(3):185-193. https://doi.org/10.1051/ fruits/2013066

41. Liao W, Chen L, Ma X, Jiao R, Li X, Wang Y (2016) Protective effects of kaempferol against reactive oxygen species-induced hemolysis and its antiproliferative activity on human cancer cells. Eur J Med Chem 114:24-32. https://doi.org/10.1016/j.ejmech.2016.02.045

42. Welbourn EM, Wilson MT, Yusof A, Metodiev MV, Cooper CE (2017) The mechanism of formation, structure and physiological relevance of covalent hemoglobin attachment to the erythrocyte membrane. Free Radic Biol Med 103:95-106. https://doi.org/10.1016/j.freeradbiomed.2016.12.024

43. Chansiw N, Paradee N, Chotinantakul K, Srichairattanakool S (2018) Antihemolytic, antibacterial and anti-cancer activities of methanolic extracts from leaves and stems of Polygonum odoratum. Asian Pac J Trop Biomed 8(12):580

44. Derouich M, Bouhlali EDT, Bammou M, Hmidani A, Sellam K, Alem C (2020) Bioactive compounds and antioxidant, Antiperoxidative, and Antihemolytic properties investigation of three Apiaceae species grown in the southeast of Morocco. Scientifica 2020:9. https://doi.org/10.1155/2020/3971041

45. Bhat SH, Ullah MF, Abu-Duhier FM (2019) Anti-hemolytic activity and antioxidant studies of Caralluma quadrangula: potential for nutraceutical development in cancers and blood disorders. Int J Pharm Res Allied Sci 8(4): $121-129$

\section{Publisher's Note}

Springer Nature remains neutral with regard to jurisdictional claims in published maps and institutional affiliations.

\section{Submit your manuscript to a SpringerOpen ${ }^{\circ}$ journal and benefit from:}

- Convenient online submission

- Rigorous peer review

- Open access: articles freely available online

High visibility within the field

- Retaining the copyright to your article

Submit your next manuscript at $\boldsymbol{\nabla}$ springeropen.com 